MARY SUN D

BRITNEY WILSON

JENNIFER MURASE

GARY BUTTS

*Author affiliations can be found in the back matter of this article
凹

Levy

Library

Press

\title{
ABSTRACT
}

Purpose: Positive relationships between patients and providers improve the quality of healthcare delivery and lead to better health outcomes. However, these experiences are systemically threatened by implicit bias and stereotype threat, two social phenomena that differentially affect minority groups and often potentiate each other. The automatic associations underlying implicit bias can perpetuate experiences of stereotype threat, an adverse psychological predicament that occurs when an individual who has internalized negative stereotypes about their social group and/or other diverse identities is put in a situation where they must confront those stereotypes. Stereotype threat contributes to racial and gender performance gaps, many of which exist in medicine. Biases can negatively affect the care received by minority patients, discourage those patients from seeking care, and contribute to the myriad barriers experienced by minority providers, ultimately amplifying existing healthcare disparities.

To address implicit bias and stereotype threat in clinical interactions, we take a transformative learning approach to the development of digital teaching curricula for medical trainees and physicians. While the principles of our curriculum are generalizable and can be expanded, our current efforts are intended for dermatology. Dermatology is one of the least racially diverse specialties, where access to race-concordant visits is limited for minority patients.

Methods: Consensus methods were used to synthesize evidence-based conceptual frameworks relevant to implicit bias and stereotype threat. Transformative learning theory informed the instructional design, which incorporates active learning exercise alongside didactic instruction.

CORRESPONDING AUTHOR:

\section{Mary Sun}

Icahn School of Medicine at Mount Sinai, US

mary.sun@icahn.mssm.edu

\section{KEYWORDS:}

stereotype threat; implicit bias; diversity and inclusion; skin of color; dermatology; digital technology

\section{TO CITE THIS ARTICLE:}

Sun M, Wilson B, Murase J, Butts G. Addressing Implicit Bias and Stereotype Threat in the Clinical Encounter: A Digitally-Enabled Transformative Learning Approach to Address Healthcare Disparities in Dermatology and Beyond. ISMMS Journal of Science and Medicine. 2021; 1(2): 7, pp. 1-2. DOI: https://doi. org/10.29024/ijsm.54 
Results: We have collated implicit bias and stereotype threat teaching materials, to be structured as digital streaming modules, intended to assist dermatology trainees and providers with addressing situations of implicit bias and stereotype threat that may occur in clinic. The curriculum steps through hypothetical patient visits to identify susceptible elements throughout the dermatologic encounter. A threepoint action plan is presented to participants for future use in clinical settings and focuses on increasing representation within all aspects of the patient visit, employing communication techniques to understand patient perspectives, and empathically fostering connection.

Conclusion: Our innovative course can be applied to achieve skill development for dermatology providers in recognizing and managing implicit bias and stereotype threat. We are currently developing a protocol to assess the impacts of our curriculum on the clinical experiences of minority patients. Furthermore, we are working with the Diversity Innovation Hub to launch a service-learning fellowship opportunity for medical students. Ultimately, we hope this work can improve the quality of patientdoctor relationships in clinical settings and affect better health outcomes for minority patients.

\section{COMPETING INTERESTS}

The authors have no competing interests to declare.

\section{AUTHOR AFFILIATIONS}

Mary Sun (D) orcid.org/0000-0003-3964-3858

Icahn School of Medicine at Mount Sinai, US

\section{Britney Wilson}

Memorial Sloan Kettering Cancer Center, US

\section{Jennifer Murase}

University of California San Francisco, US

\section{Gary Butts}

Mount Sinai Health System, US; Icahn School of Medicine at Mount Sinai, US
ISMMS Journal of Science

and Medicine

DOI: $10.29024 / \mathrm{ijsm} .54$
TO CITE THIS ARTICLE:

Sun M, Wilson B, Murase J, Butts G. Addressing Implicit Bias and Stereotype Threat in the Clinical Encounter: A Digitally-Enabled Transformative Learning Approach to Address Healthcare Disparities in Dermatology and Beyond. ISMMS Journal of Science and Medicine. 2021; 1(2): 7, pp. 1-2. DOI: https://doi. org/10.29024/ijsm.54

Submitted: 14 April 2021

Accepted: 14 April 2021

Published: 12 May 2021

\section{COPYRTGHT:}

(c) 2021 The Author(s). This is an open-access article distributed under the terms of the Creative Commons Attribution 4.0 International License (CC-BY 4.0), which permits unrestricted use, distribution, and reproduction in any medium, provided the original author and source are credited. See http://creativecommons.org/ licenses/by/4.0\%.

ISMMS Journal of Science and Medicine is a peer-reviewed open access journal published by Levy Library Press. 